\title{
MANAGEMENT OF DEGLOVING INJURIES OF THE HAND USING ABDOMINAL FLAPS- A RELIABLE AND DURABLE RECONSTRUCTIVE OPTION
}

\author{
Arvind Lakshmana Rao', Jabez Gnany²
}

${ }_{1}^{1}$ Associate Professor, Department of Plastic Surgery, Father Muller Medical College Hospital, Mangaluru. 2Postgraduate Student, Department of Orthopaedics, Father Muller Medical College Hospital, Mangaluru.

\section{ABSTRACT}

\section{BACKGROUND}

Degloving injuries of the hand are quite common due to industrial injuries and road traffic accidents. In most of the cases, only the skin and subcutaneous tissue is avulsed leaving behind intact tendons and vessels. Early debridement and immediate flap cover are vital to prevent infection and to restore proper hand function. Delayed intervention and skin grafting over the exposed tendons result in compromised function of the hand. We describe abdominal flap as a durable option to cover these degloved hands.

The aim of this study was to evaluate the effectiveness of abdominal flap as a reconstructive option to manage the avulsion injury of hand due to industrial injuries and road traffic accidents.

\section{MATERIALS AND METHODS}

The present study includes case series of 30 degloving injury of hand treated by abdominal flaps, in the Department of Plastic Surgery and Orthopaedics at Father Muller Medical College and Hospital, Mangalore between August 2015 and January 2017. Patient demographic data, medical histories, comorbidities, defect characteristics, hospitalization, complications and follow-up were evaluated and presented as uncontrolled case series.

Exclusion criteria included patients with vascular injury, Peripheral vascular disease and uncontrolled diabetes.

\section{RESULTS}

The ages of the subjects were ranging from 8 to 38 years with an average of 20.8 years. The procedure was performed in two stages- thorough debridement and inset of the flap to the defect, followed by division of the flap after 3 weeks. The average duration of surgery was 80 minutes [range $60-120$ mins]. The defect in the abdomen after flap elevation was closed primarily with the help of undermining and tension sutures. A closed suction drain was kept after primary closure for 5 days to avoid seroma collection. Adhesive plaster strips were used to tie shoulder, arm and forearm to the patient's trunk, so as to avoid shearing of flap from hand defect. All the abdominal flaps were healthy. Patients were discharged after 3-5 days and advised to get dressing once in 3 days. Flap was divided after 3 weeks and final inset of the flap to the defect was done. Physiotherapy was started immediately and continued for a period of 2 months. All the patients showed marked improvement in hand function and could return back to their work. The operated patients were followed up for 6 months.

\section{CONCLUSION}

Abdominal flap is one of best tools in reconstructing degloving injury of the hand. It gives a durable cover to the exposed tendons and facilitates early mobilisation and preservation of hand function.

\section{KEYWORDS}

Abdominal flap, degloving hand injury, avulsion of hand, Flap covers for hand.

HOW TO CITE THIS ARTICLE: Rao AL, Gnany J. Management of degloving injuries of the hand using abdominal flaps- a reliable and durable reconstructive option. J. Evolution Med. Dent. Sci. 2018;7(09):1096-1100, DOI: 10.14260/jemds/2018/249

\section{BACKGROUND}

Degloving injuries of the hand are quite common due to industrial injuries and road traffic accidents. In most of the cases, only the skin and subcutaneous tissue is avulsed leaving behind intact tendons and vessels. Early debridement and immediate flap cover are vital to prevent infection and to restore proper hand function.

Even though there is no defined algorithm for upper limb reconstruction, free flaps are considered to be the first option. 1,2

'Financial or Other Competing Interest': None.

Submission 16-01-2018, Peer Review 08-02-2018,

Acceptance 15-02-2018, Published 26-02-2018.

Corresponding Author:

Dr. Jabez Gnany,

Father Muller Medical College Hospital,

Mangaluru-575002.

E-mail: jabezgnany@gmail.com

DOI: $10.14260 /$ jemds $/ 2018 / 249$
There have been a variety of free flaps described for intervention, ${ }^{3}$ the most common amongst them being the adipofascial flaps.

Some hand defects have been successfully covered using temporoparietal fascia(4-6) oromental flaps. ${ }^{7}$ The advantage associated with these flaps is that it allows for a thin coverage that permits tendon gliding as well as secondary procedures. The omental flap is not popular since it involves a laparotomy. ${ }^{8}$

Abdominal flaps still continue to be the simple and effective tool in the armamentarium of a Plastic surgeon. The procedure of abdominal flaps is less complicated and time consuming when compared to free flaps. The chances of flap necrosis are very rare.

\section{MATERIALS AND METHODS}

The present study includes case series of 30 degloving injury of hand treated by abdominal flaps, at Father Muller Medical College and Hospital, Mangalore between August 2015 and January 2017. Patient demographic data, medical histories, 
comorbidities, defect characteristics, hospitalization, complications and follow-up were evaluated and presented as uncontrolled case series.

\section{Exclusion Criteria}

Patients with vascular injury, Peripheral vascular disease and uncontrolled diabetes.

\section{Preoperative Planning}

Detailed history on mode of injury and associated medical illness was taken. Anteroposterior and oblique/lateral radiographs of the affected extremity were taken for all patients followed by sterile dressing of the wound. Routine blood investigations were done, and necessary and adequate treatment was given for those associated with medical problems before taking them to surgery following written consent. Intravenous antibiotics was given an hour before the surgery.

\section{Flap Planning and Design}

The avulsed skin was debrided, and haemostasis was maintained. The remaining defect was measured, and a template was prepared. The template was placed on the abdomen and boundaries of the flap were marked. The flap was marked lateral to the umbilicus on the same side of the hand defect. The flap was based superiorly. Extra length of the flap was taken to facilitate the movement of hand after flap inset.

\section{Surgical Technique}

The incision was made on the boundaries of the flap markings. The base of the flap was kept wide enough to facilitate proper blood supply to the flap. The incision was deepened till the anterior rectus sheath and the flap was elevated inferosuperiorly. All the musculocutaneous perforators were isolated and cauterized using bipolar cautery. The flap was held by the assistant using skin hooks, while dissecting the flap. After the completion of the flap elevation, the donor area of the harvested flap was closed primarily. A suction drain was kept to avoid collection of seroma. This was made easy by undermining the edges and far-near-near-far tension sutures. Then Vicryl 4-0 was used to suture dermis. The skin staplers were used for the skin closure. Tension sutures were cut after closure of skin. The elevated flap was sutured to the hand defect using 4-0 Ethilon. Lubricant gauze and surgical pads were kept beneath the flap to absorb the collection. Adhesive plaster strips were used to fix patient's shoulder, elbow and hand to the trunk to avoid shearing of flap. Sand bag or a small pillow was kept below the elbow for support. Patients were discharged after 3-5 days and advised dressing twice a week till 21 days. Flap division and final inset was done after 3 weeks. Then the patients were subjected to aggressive physiotherapy.

\section{RESULTS}

The ages of the subjects were ranging from 8 to 38 years with an average of 20.8 years. The procedure was performed in two stages- thorough debridement and inset of the flap to the defect, followed by division of the flap after 3 weeks. The average duration of surgery was 80 minutes [range $60-120$ mins]. The abdomen defect after flap elevation was closed primarily with the help of undermining and tension sutures.
A closed suction drain was kept after primary closure for 5 days to avoid seroma collection. Adhesive plaster strips were used to tie shoulder, arm and forearm to the patient's trunk, so as to avoid shearing of flap from hand defect. All the abdominal flaps survived well. Patients were discharged after 3 - 5 days and advised to get dressing once in 3 days. Flap was divided after 3 weeks and final inset of the flap to the defect was done. Physiotherapy was started immediately and continued for a period of 2 months. All the patients showed marked improvement in hand function and could return back to their work. Compression garments were used for all patients, one month following final inset. Use of compression garments has reduced the bulk of the flap considerably. Debulking of the flap was done after 3 months for 4 patients. The operated patients were followed up for 6 months. All patients showed good improvement in hand function.

\section{RESULTS CASE 1}

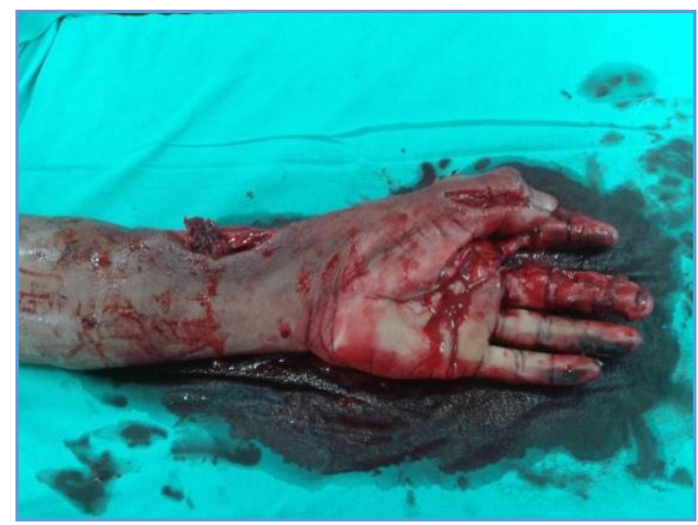

Figure 1. Deglove injury left hand

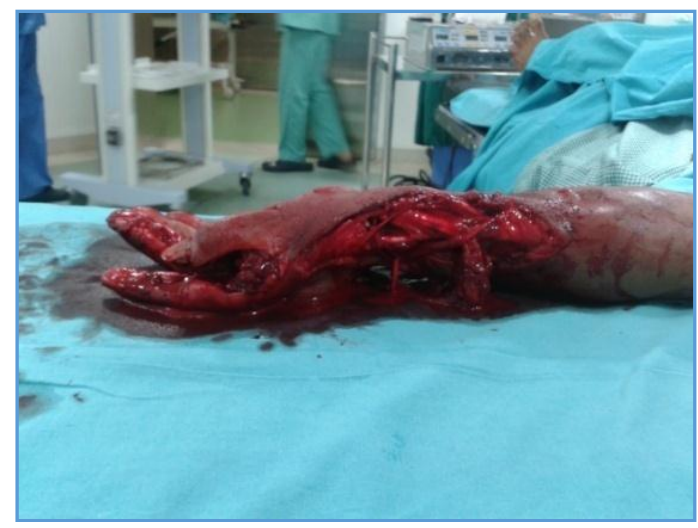

Figure 2. Bone and tendons exposed

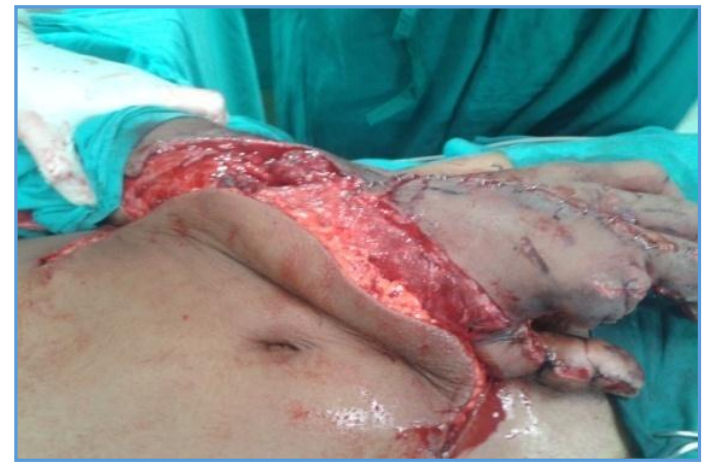

Figure 3. Abdominal flap raised 


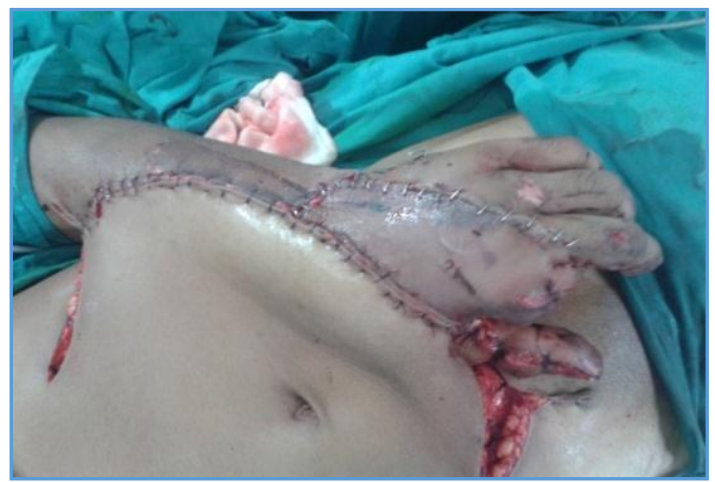

Figure 4. Abdominal flap

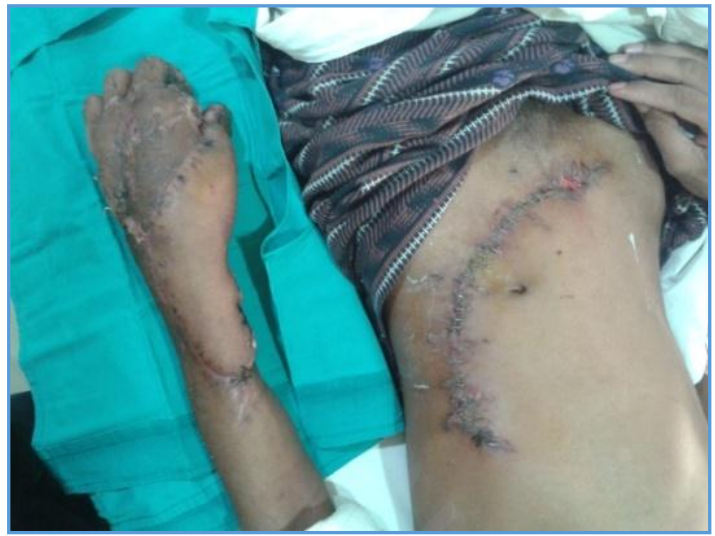

Figure 5. 3 weeks post-op

\section{CASE 2}

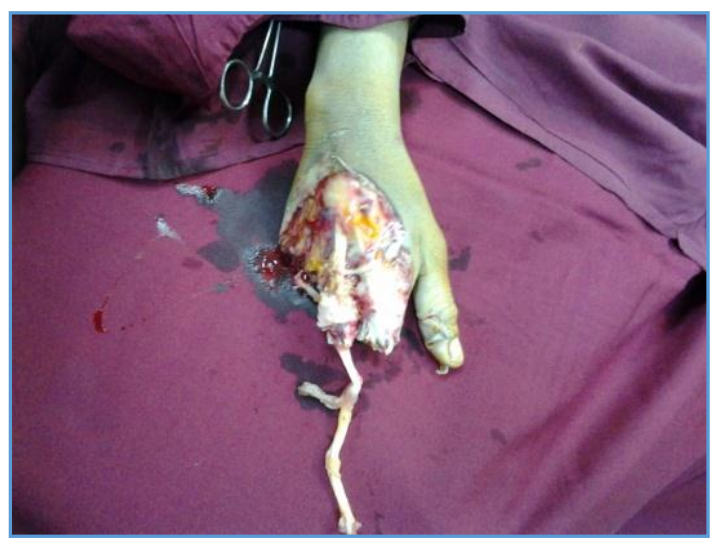

Figure 6. Crush injury right hand

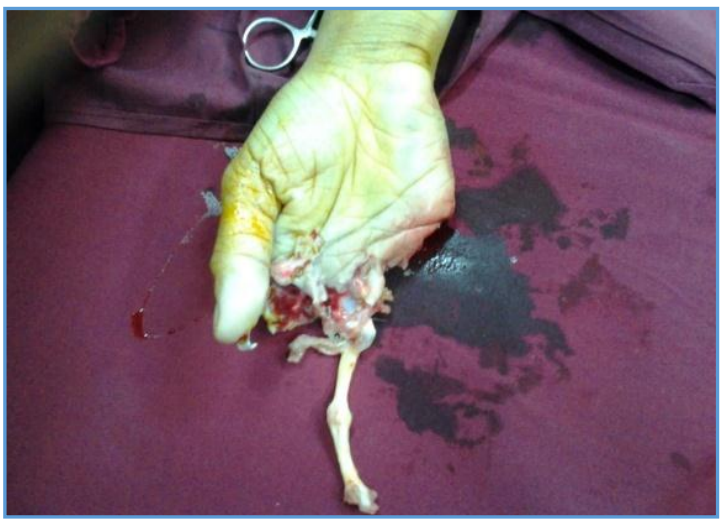

Figure 7. Volar aspect of hand

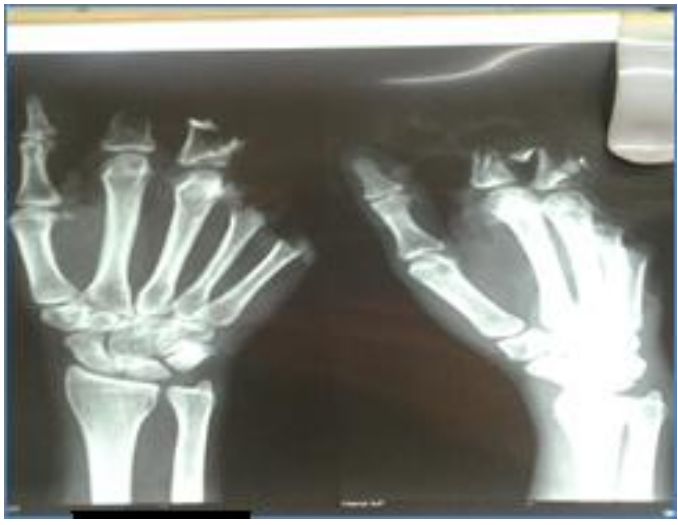

Figure 8. X-ray showing bone loss

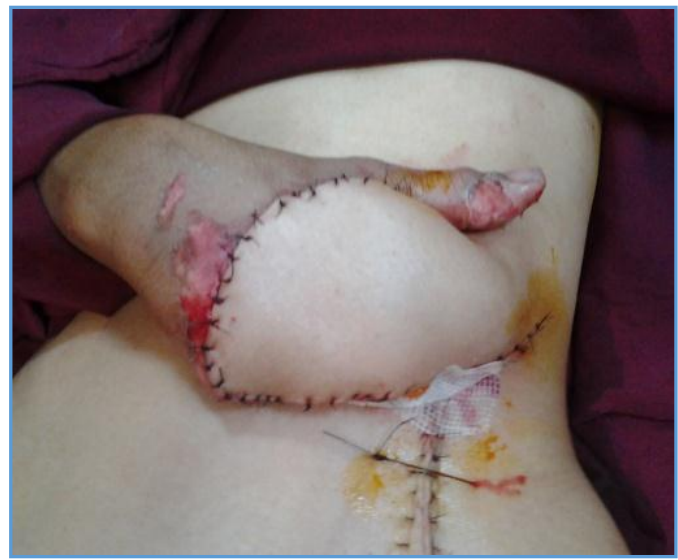

Figure 9. Abdominal flap

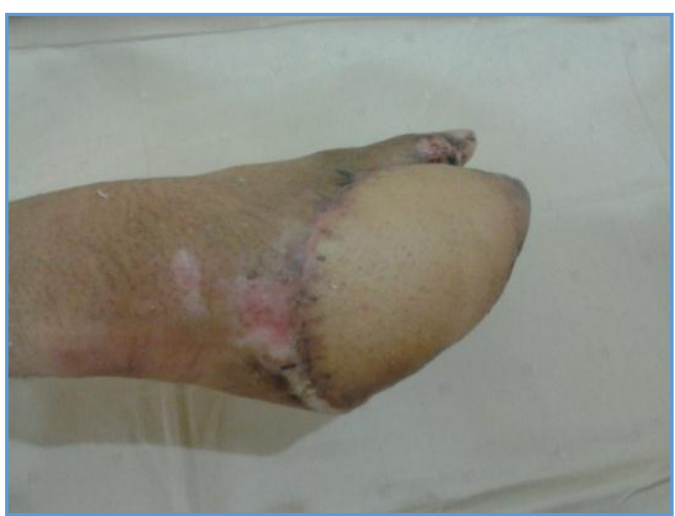

Figure 10. 3 months post-op

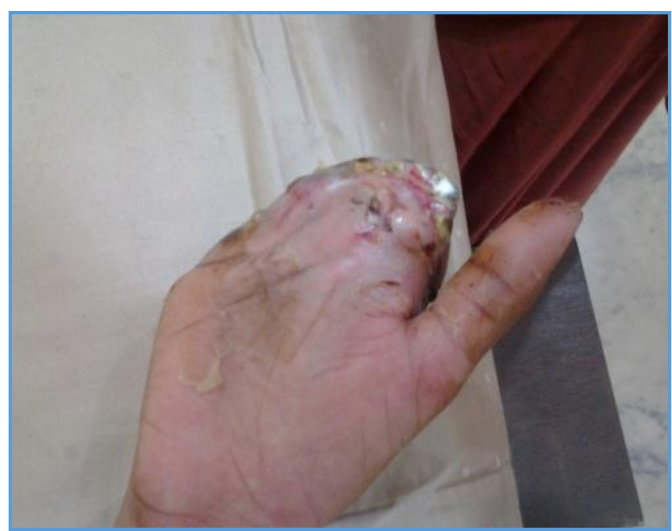

Figure 11. 3 months post-op 


\section{CASE 3}

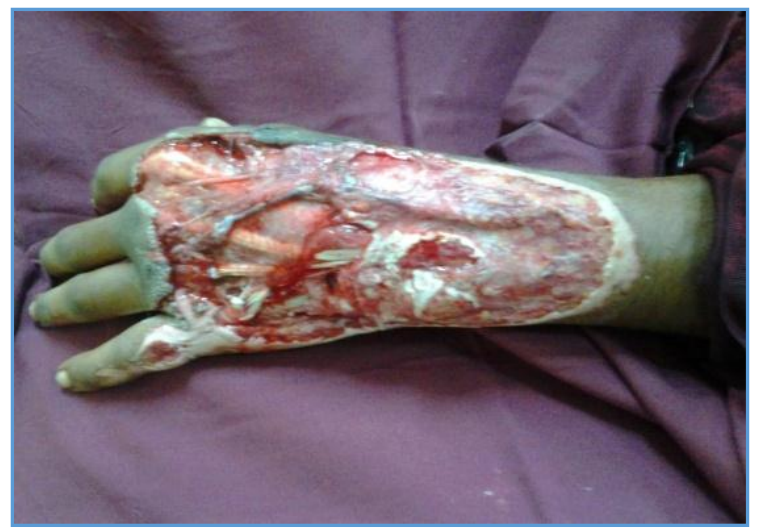

Figure 12. Deglove wound over left hand-dorsum

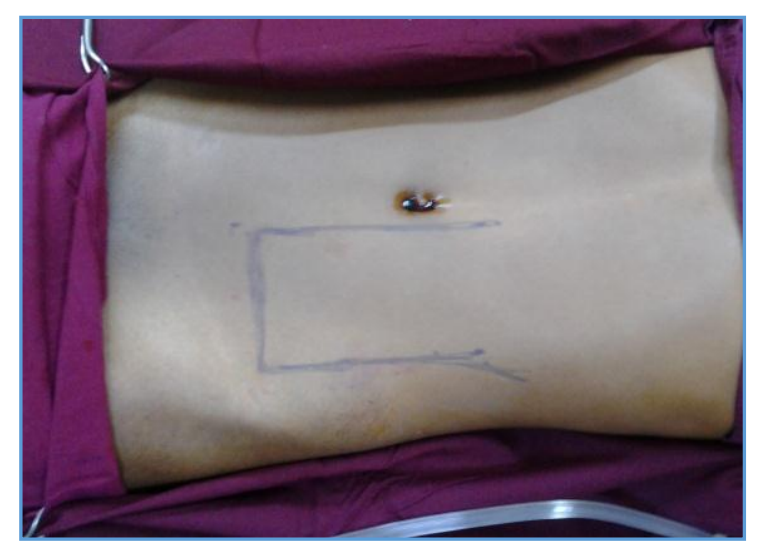

Figure 13. Flap marked

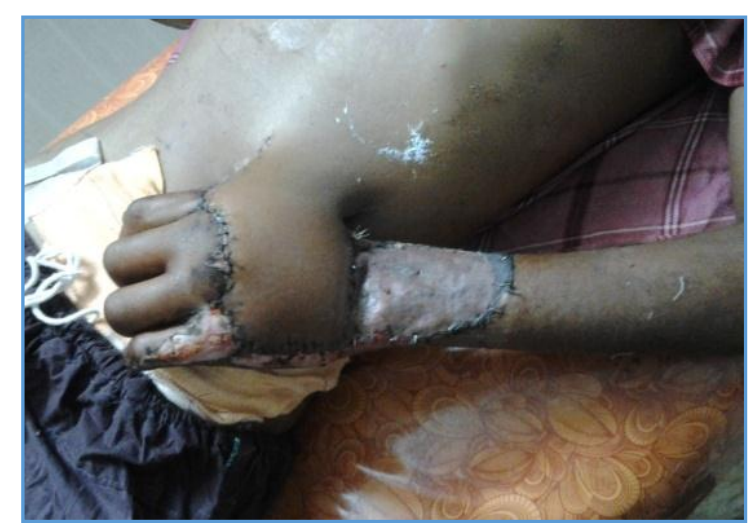

Figure 14. Flap with skin grafting

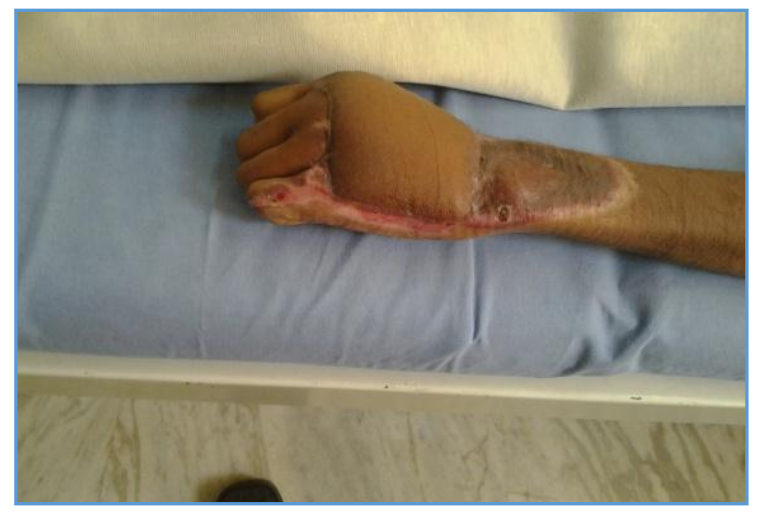

Figure 15. Post flap division

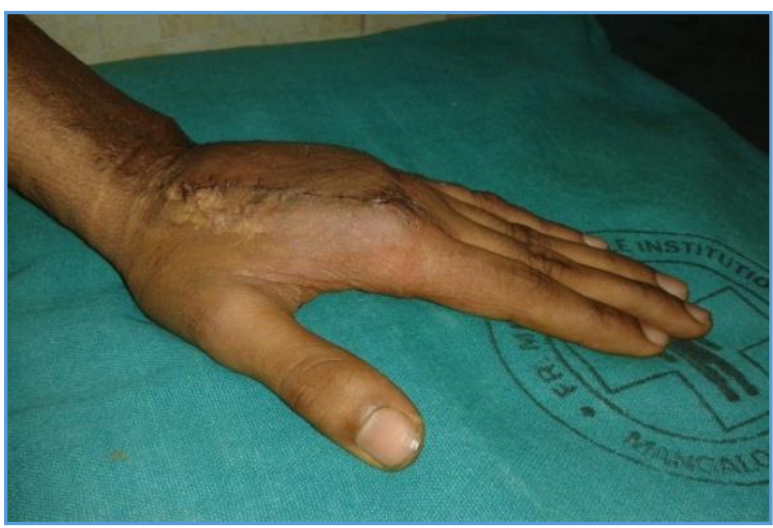

Figure 16. Post debulking of abdominal flap

\section{DISCUSSION}

Abdominal flaps are workhorses for hand reconstruction after trauma and can also be used to cover post burn contracture and post tumour excision of hand. The procedure of abdominal flap is very simple and has less chance of flap necrosis. ${ }^{9}$ Abdominal flap can be done in age group varying from neonate to 40. Children co-operate well for the procedure and abdominal flap is preferred over free flaps in kids. In children aged less than 2 years, free flap coverage is more difficult than it is in older children mainly because of the size of the blood vessels. ${ }^{10,(11-12)}$

The treatment involving degloving injuries is one of the most difficult problems faced in hand surgery. Good cosmetic results form an essentiality in finger degloving injuries along with functional results. In single- or multiple finger degloving injuries, treatment by microsurgical replantation usually yields good functional and cosmetic results. ${ }^{13}$ However, microsurgical replantation is often difficult in multiple-finger degloving injuries where the skin, subcutaneous tissue and vessels are severely damaged. ${ }^{14}$

The other indications where abdominal flaps are preferred over free flap coverage are mutilating hand injuries, extensive degloving injuries and complex digital defects located on both dorsal and palmar aspects and in case of length preservation of multiple digit amputations.10,(12-15)

Microsurgical replantation is often difficult in multiplefinger degloving injuries where the skin, subcutaneous tissue and vessels are severely damaged. Abdominal flap procedure does not require special microvascular expertise and long duration of surgery could be avoided. Conventional abdominal and groin flaps are easy, safe and useful procedures, but these flaps have thick layer of subcutaneous fat, which results in a puffy and bulky shape. ${ }^{16}$

Abdominal flap provides flexible and durable cover over exposed tendons, which facilitates faster physiotherapy and return of normal finger movements. However, some patients may require debulking procedure to improve aesthetic appearance. ${ }^{17}$

The expenditure associated with abdominal flaps is less compared to that of micro-surgical reconstruction. Our patients were discharged after 3-5 days and later advised dressings in outpatient clinics, thereby reducing the duration of stay in the hospital and the cost of treatment. Even though the abdominal flap is a staged procedure, flap division and debulking procedures were done as day care procedures under local anaesthesia with minimal hospital expense. 
Abdominal flaps are not suitable for patients aged above 40 years due to the possibility of shoulder rigidity and pain. However, aggressive physiotherapy restores normal function in most patients. Pedicled flaps have an inherent advantage due to their vascularity pattern; rapid thinning is possible during secondary procedures. The skin attachment is maintained as far as possible and the flap can be thinned almost to the sub dermal level. ${ }^{9}$

\section{CONCLUSION}

Abdominal flaps provide a stable and protective cover in degloving injuries of the hand and thus favour early rehabilitation and return of finger mobility in patients. The abdominal flap procedure is cost effective when compared to free flap cover and microsurgical expertise and stringent post-operative monitoring is not required. The procedure is easy to learn, and results are very predictable and hence can be performed by a young plastic surgeon and general surgeon as well. However, the surgery is staged, and the morbidity of hand being attached to the trunk and the associated discomfort is to be borne by the patients. Due to small size of vessels, abdominal flap is the first choice of procedure in children. Secondary procedures like flap division and debulking are minor day care procedures which will neither require admission nor cause financial burden to the patient.

\section{REFERENCES}

[1] Vedder N, Hanel D. The mangled upper extremity. Wolfe, Hotchikiss, Pederson, et al. eds. Green's Operative hand surgery. $6^{\text {th }}$ edn. Philadelphia, PA: Elsevier 2011: p. 1603-44.

[2] Pederson WC. Upper extremity microsurgery. Plastic Reconstruction Surgery 2001;107(6):1524-37.

[3] Hallock GG. The utility of both muscle and fascia flaps in severe upper extremity trauma. Journal of Trauma 2002;53(1):61-5.

[4] Kruavit A, Visuthikosol V. Bilateral temporoparietal fascial free flaps for reconstruction of bilateral hand defects: a report of two cases. Microsurgery 2009;29(8):662-6.

[5] Pujo J, Barbary S, Simon E, et al. Les transfertsvascularisés de fascia temporalis dans les pertes de substance de la main. À propos de troiscas Ann Chir Plast Esthet 2010;55(1):61-5.

[6] Upton J, Rogers C, Durham-Smith G, et al. Clinical applications of free temporoparietal flaps in hand reconstruction. Journal of Hand Surgery 1986;11(4):475-83.

[7] Seitz I, Williams CS, Wiedrich TA, et al. Omental freetissue transfer for coverage of complex upper extremity and hand defects--the forgotten flap. Hand (N Y) 2009;4(4):397-405.

[8] Kim SW, Lee HJ, Kim JT, et al. Multiple-digit resurfacing using a thin latissimus dorsi perforator flap. Journal of Plastic Reconstruction and Aesthetics Surgery 2014;67(1):74-80.

[9] Bajantri B, Latheef L, Sabapathy SR. Tips to orient pedicled groin flap for hand defects. Tech Hand Up Extrem Surg 2013;17(2):68-71.

[10] Al-Qattan M, Al-Qattan AM. Defining the indications of pedicled groin and abdominal flaps in hand reconstruction in the current microsurgery era. The Journal of Hand Surgery 2016;41(9):917-27.

[11] McGregor IA, Jackson IT. The groin flap. British Journal of Plastic Surgery 1972;25(1):3-16.

[12] Smith PJ, Foley B, McGregor IA, et al. The anatomical basis of the groin flap. Plastic Reconstruction Surgery 1972;49(1):41-7.

[13] Adani R, Castagnetti C, Landi A. Degloving injuries of the hand and fingers. Clinical Orthopaedic Relat Res 1995;314:19-25.

[14] Tseng OF, Tsai YC, Wei FC, et al. Replantation of ring avulsion of index, long and ring fingers. Ann Plast Surg 1996;36(6):625-8.

[15] Lister GD, McGregor IA, Jackson IT. The groin flap in hand injuries. British Journal of Plastic Surgery 1973;4(3):229-39.

[16] Yamada N, Ui K, Uchinuma E. The use of a thin abdominal flap in degloving finger injuries. British Journal of Plastic Surgery 2001;54(5):434-8.

[17] Lee JH, Burm JS, Kang SY, et al. Full thickness skin grafting with de-epithelization of the wound margin for finger defects with bone or tendon exposure. Archives of Plastic Surgery 2015;42(3):334-40. 